\title{
LA HISTORIA QUE VIENE
}

\author{
Carlos Barros \\ Universidad de Santiago
}

\begin{abstract}
RESUMO: Bajo la forma de 16 tesis, que hacen referencia la cambio de paradigmas que está teniendo lugar en la disciplina de la historia, a finales del siglo XX, el autor refleja, a modo de conclusión provisional, los resultados del I Congreso Internacional Historia a Debate, realizado bajo su coordinación en Santiago de Compostela (España) en 1993, tratando de delimitar los últimos debates y consensos sobre la escritura de la historia, al objeto de que la comunidad de historiadores pueda tomar conciencia de estos cambios y, en su caso, reorientarlos. El punto de partida metodológico que se propone para el estudio de esta evolución historiográfica son los conceptos de "paradigma", "comunidad de especialistas" y "revolución científica" según el historiador de la ciencia Thomas S. Kuhn.
\end{abstract}

PALAVRAS-CHAVE: Historia, Historiografía, Paradigma, Debate, Kuhn.

ABSTRACT: In 16 theses the author discusses the changing of paradigm in the discipline of History, reflecting upon the results of the I International Congress "Debating History", that took place in Santiago de Compostela (Spain) in 1993 and was organized by him. The article sistemathizes the debates on the writing of History aiming to publish the changes that are occuring in this domain. The methodological starting point adopted in the study of this evolution in the historiography are Thomas Kuhn's concepts of "paradigm", "community of specialists" and "scientific revolution".

KEYWORDS: History, Historiography, Paradigm, Scientific Revolution, Kuhn.

La manera de escribir la historia implantada entre los historiadores profesionales a partir de la II Guerra Mundial, la historia entendida como ciencia, de cuya puesta en práctica resultó una historia económico-social, estructural y objetivista, que propugnó la ambición ideal de una historia total y la necesidad de estudiar el pasado para comprender el presente y construir un futuro mejor, ha sido fuertemente cuestionada a lo largo de la pasada década, al tiempo que entró en crisis el proyecto filosófico común que la sustentaba, la idea ilustrada del progreso.

Hasta aquí la evidencia. Resulta menos claro para todos, y la razón de ser de este trabajo es intentar explicitarlo, el hecho de que la comunidad de historia- 
dores ha ido formulando, a la vez que la crítica, nuevos consensos sobre cómo ejercer la profesión, con frecuencia sin saberlo, porque el proceso de las nuevas convergencias se produce más en la práctica que como consecuencia de un debate explícito. Por algo se dice, y con mucha razón, que la crisis finisecular de la historia - pensemos sobre todo en el papel decreciente de los historiadores y de la historia en la sociedad- está acompañada de un formidable incremento de la producción historiográfica, que ha renovando enormemente temas y métodos, pero de una manera desigual, sin demasiada reflexión, sin orden ni concierto, lo que limita gravemente y aun puede dar al traste con los posibles resultados. Nuestras primeras propuestas quieren ser, justamente, sobre la forma en que las comunidades científicas, en general, reconstruyen, a través de procesos críticos, su acervo común.

Nos interesa más, en esta ocasión, saber qué historia se hace y, sobre todo, qué historia se debe hacer -con lo cual sobrepasamos, consciente y críticamente, la función notarial-, que las reprobaciones, en algunos frentes muy generalizadas, a las "nuevas historias" que han caracterizado las historiografías del siglo XX, y cuya vigencia en gran medida no dejamos de reivindicar, siempre y cuando aceptemos - desechando por tanto cualquier espíritu numantino- todo aquello que está superado por la práctica científica en general, y por la práctica de los historiadores en particular, así como las nuevas necesidades sociales, culturales y generacionales, a las que la historia y las ciencias sociales deben responder en este acelerado fin de siglo, iniciado en 1989, que en un principio impulsó tremendamente las críticas posmodernistas -y más aún las premodernistas- para en un breve plazo animar una racionalidad renovada, una nueva ilustración, una reformulación de la idea de progreso que tome en consideración errores y fracasos, esfuerzo intelectual con el que nos sentimos identificados.

Enunciaremos brevemente, mediante 16 tesis o proposiciones argumentadas, los criterios que nos parecen fundamentales para alcanzar el nuevo consenso historiográfico en proceso de gestación, con el fin de alentar el debate contribuyendo a centrarlo y promoviendo la disidencia, conscientes de que todavía estamos en el camino: no ha terminado la transición al paradigma historiográfico común del siglo XXI, ni siquiera es inevitable.

\section{1}

La historiografía avanza a saltos, y no por simple acumulación, según las decisiones consensuadas en cada momento por la comunidad de historiadores.

En cualquier libro de historiografía que se precie, se explica el progreso del conocimiento histórico jalonado por rupturas en la forma de escribir la historia. Han sido particularmente importantes: el cambio traumático de la historia metafísica, sagrada o literaria, a la historia positivista en el siglo XIX, y la revolución historiográfica del siglo XX, protagonizada por la escuela de Annales y el materialismo histórico, contra el concepto positivista de la historia. Precisamente este modo de concebir la historia de la historia, a través de revoluciones disciplinares, es deudor de la concepción materialista de la historia.

Pues bien, Thomas S. Kuhn, un físico reconvertido en historiador de la ciencia, aplicando a su manera el método de la historia al devenir del conocimiento científico, singularmente referido a las ciencias de la naturaleza, ha revolucionado la filosofía de la ciencia a partir de los años 60 , poniendo en muy graves aprietos a las, en aquel momento, dominantes concepciones neopositivistas (encabezadas por Popper) que han coartado, mucho más de lo que se piensa, el desarrollo del programa historiográfico inicial del materialismo histórico y de Annales.

A diferencia de los positivistas, viejos y nuevos, Kuhn sitúa el origen de las certidumbres científicas más en las decisiones sucesivamente consensuadas, tras períodos de crisis y de rivalidad de teorías, por 
la comunidad científica de cada disciplina, que en la verificación (o falsación) empírica, por lo demás indispensable. La aplicación a las ciencias sociales y humanas de los descubrimientos de Khun se infiere de sus propias deudas explicitadas con la historia -y también con la sociología, la psicología social y la epistemología (KUHN, 1975, p.3), al estudiar la historia de las ciencias físicas, y más aún de la propia experiencia de la historiografía, que no por casualidad suscita hoy la atención creciente de los historiadores, que así y todo nunca ha llegado tan lejos, como Kuhn, a la hora de sistematizar teóricamente la evolución histórica de la ciencia, en nuestro caso, la ciencia de la historia.

En las pasadas décadas, el interés de Kuhn y de otros científicos por la historia no se ha correspondido con un interés recíproco de los historiadores por la historia de la ciencia y la filosofía de la ciencia. La razón reside en la separación vigente, a menudo teñida de animadversión, entre ciencias y letras (SNOW, 1977), entre ciencias "duras" y ciencias sociales y humanas, debido a la cual pasó desapercibido el ulterior "ablandamiento" de las ciencias físicas. Cuando, excepcionalmente, ha existido una relación entre historia y ciencia estricta, se ha establecido con la ciencia neopositivista -por ejemplo, para importar métodos cuantitativos-, pese a la hostilidad manifiesta de Karl Popper hacia todo historicismo. Por lo demás, el espontáneo desinterés del historiador de oficio hacia la teoría, viene a remachar este décalage entre investigación histórica e historiográfica y filosofía de la ciencia, últimamente la rama más productiva de la filosofía.

La salida a la actual crisis de identidad y de crecimiento de la disciplina histórica, pasa, en nuestra opinión, por la aplicación de la teoría de Kuhn sobre el desarrollo histórico de las ciencias.

\section{2}

Existe un paradigma común de los historiadores, hoy en plena crisis, cuya resolución plena no será posible más que con la sustitución por un paradigma nuevo.

Entendemos por paradigma común el conjunto de compromisos compartidos por una comunidad científica dada: aquellos elementos teóricos, metodológicos y normativos, creencias y valores, que gozan en un momento determinado del consenso de los especialistas. Un paradigma global está, a su vez, formado por paradigmas parciales. El funcionamiento de un paradigma común es consustancial con la existencia de una disciplina unificada, se justifican mutuamente, y no excluyen la pluralidad de enfoques, incluso de escuelas, más bien lo contrario: nunca encontraremos plena homogeneidad teórica y metodológica entre los miembros de una comunidad establecida, ni tampoco es aconsejable en aras de la buena marcha de una disciplina científica. El concepto historiográfico de paradigma ha sido precisamente creado por Kuhn para explicar los mecanismos reales de aprendizaje y consenso, en el interior de cualquier comunidad madura de científicos, necesariamente más flexibles y abiertos que los propios de una escuela con su teoría, sus líderes y su jerarquía. La historia científica, más allá de las escuelas historiográficas y de las historiografías nacionales, no habría podido establecerse sin un paradigma común.

El reconocimiento subjetivo del paradigma común de los historiadores del siglo XX, tropieza de entrada con dos problemas. La relativa rivalidad de las dos grandes escuelas historiográficas, Annales e historiografía marxista, que han articulado -por vez primerael paradigma común historiográfico a mediados del siglo XX, combatiendo exitosamente la historia tradicional: acontecimental, política, narrativa, biográfica. Y la persistencia de un tercer componente positivista, raramente admitido por los nuevos historiadores, que se refleja en el carácter manifiestamente empírico que ha seguido impregnando el oficio de historiador, con lo que tiene de positivo (crítica y uso de fuentes) y de negativo (desprecio por la reflexión y la teoría). 
Con independencia del grado de conciencia que tenga tal o cual historiador, o del grado de aceptación de dicho consenso por parte de ésta o aquella escuela o historiografía nacional, el paradigma común de los historiadores existe y funciona. Entre los compartidos paradigmas parciales que constituyen el ahora ya viejo paradigma general del siglo $\mathrm{XX}$, que conocemos como la historia científica, hay que contar con los siguientes: historia total, pasado/presente/futuro, historia-ciencias sociales, historia explicativa, historia económico-social, fuentes no narrativas, cuantitativismo, monografías regionales, multiplicidad de tiempos.

La puesta en práctica del paradigma Annalesmarxismo, a partir de la segunda mitad del siglo XX, ha sufrido, no obstante, severas limitaciones y desviaciones a causa de sus propios defectos, y de la pervivencia del positivismo en el método y la teoría, portador de un objetivismo muy pronto eficazmente reforzado por el economicismo marxista y por el estructuralismo (el paradigma estructuralista dominó ampliamente a las ciencias sociales, por lo menos hasta 1968).

Tres fracasos sucesivos e interrelacionados del paradigma común del siglo XX, han abierto y alimentado la crisis actual, y las reacciones puntuales de los historiadores a ella:

1) De la historia objetivista, economicista, cuantitativista, estructuralista, que da lugar en los años 70 a un progresivo retorno del sujeto, primero social (historiografía marxista angloamericana), después mental (historia francesa de las mentalidades) y por último tradicional (biografía, historia política).

2) De la historia total, abandonada como enfoque de la investigación, proclamada como algo imposible de alcanzar pero que es necesario mantener como "horizonte utópico" de los historiadores, renunciándose después a ella en el plano de la teoría, al tiempo que -ya en los años 80- la historia se desarrolla exacta- mente en sentido contrario: fragmentándose hasta el infinito en temas, géneros y métodos.

3) De la relación pasado/presente/futuro donde falló, por ejemplo, la sensibilidad del historiador hacia el feminismo, y hacia la relación hombre- medio ambiente, que para la nueva historia, geográfica y económica, se reducía al estudio del dominio de la naturaleza por medio del trabajo, o de los condicionamientos geográficos de la sociedad. La hoy vigorosa historia de las mujeres (y lo mismo podemos decir de la historia ecológica) se desarrolló, por tanto, al margen de Annales y del materialismo histórico, sobre todo en sus comienzos, y contra los hábitos pre-teóricos de la persistente influencia positivista. Aunque donde la derrota de la historia, como parte de las ciencias sociales, ha sido más notoria es en la incapacidad para comprender, y tanto más para prever, las revoluciones de 19891991 y la transición del socialismo al capitalismo en el Este europeo, que han trastocado el sentido progresivo de la historia del siglo XX. La historia científica supo asimilar el marxismo historiográfico, pero resultó incompetente para analizar y explicar las realizaciones históricas del marxismo político.

Éstas y otras anomalías impugnan el paradigma común de la historia como ciencia social, y provocan reacciones diversas, internas y externas, que están contribuyendo, directa e indirectamente, desde los años 70, a perfilar un nuevo consenso historiográfico. Proceso de gestación, y también de dispersión e incertidumbre, cuyo buen final no está para nada garantizado. Existe también la alternativa de la marginalidad: una historia cada vez más alejada de las ciencias sociales -y naturales- y más próxima a la ficción o al interés erudito de una excelsa minoría, una historia con dificultades crecientes para hacer ver su utilidad social y su papel capital en la educación de los ciudadanos y en la investigación.

En el capítulo de las reacciones internas a la crisis del paradigma común, reseñaríamos como más 
llamativas: a) los retornos de los géneros tradicionales (historia política, biografía histórica, historia-relato), que desde el período de entreguerras creíamos ajenos a la historia científica, o sea, la "historia historizante" que parecían haber derrotado Bloch, Febvre y Braudel; b) el conservadurismo academicista de varia orientación, que quiere mantener el paradigma historiográfico del siglo XX, simulando que nada pasa o argumentando, defensivamente, que es mejor repetir indefinidamente el saber acumulado que la fragmentación y la nada; c) el revisionismo historiográfico, que, aprovechando la coyuntura ideológica de los años 80 , pretende para dar la vuelta a la historiografía de las revoluciones sociales de la modernidad (francesa e inglesa, mayormente), y de las dictaduras implantadas en el período de entreguerras en Alemania, Italia y España.

Externamente, anotemos cómo la ideología posmoderna influye sobremanera en la historiografía actual. La crítica despiadada de la idea del progreso -base filosófica común del paradigma de los historiadores contemporáneos- y el "todo vale" metodológico animan a bastantes historiadores a instalarse cómodamente en la fragmentación actual de la historia, considerando incompatible la presente libertad de temas, géneros, métodos y teorías con la vigencia de cualquier "paradigma unificador". El carácter más destructivo que constructivo del posmodernismo frena sus efectos, y lo inutiliza como alternativa historiográfica.

Los acontecimientos de 1989-1991 parecieron, en un primer momento, darle la razón a los predicadores del fin de los intentos modernos de transformar el mundo, para, en cierto sentido, quitársela de inmediato con la paradójica vuelta al poder de los ex-comunistas en casi todos los países del Este mediante elecciones. Este rápido y contradictorio proceso se reprodujo con la proclamación del "final de la historia" que hizo en 1989, antes de la caída del muro de Berlín, Francis Fukuyama, asegurando que la modernidad había llegado a su destino con la generalización, como única alternativa, de la democracia liberal. La respuesta justamente airada de los historiadores de profesión a una propuesta que choca con nuestro conocimiento de la historia -y cuestiona asimismo la continuidad de nuestra profesión-, no ha de ocultarnos la mayor enseñanza del debate sobre el "final de la historia" (y que también es deducible de la crítica posmoderna): el agotamiento de la teoría progresiva de la historia, concepto fatalista de una historia que avanza hacia un final feliz previamente fijado.

\section{3}

Es una falsa alternativa decir que la historia, como no puede ser una ciencia "objetiva" y "exacta", no es una ciencia.

El lento redescubrimiento, a lo largo de los últimos veinte años, del rol del sujeto en la historia y del libre albedrío del historiador en su trabajo, entre la cenizas de la vieja historia objetivista, economicista y estructuralista, sembró, una vez más, de dudas a la profesión acerca de la cientificidad de la historia como disciplina capaz de reproducir el pasado "tal como fue". La pervivencia de este concepto eminentemente positivista de la ciencia y de la historia según Ranke, entre los historiadores de formación annaliste y/o marxista, está por ende facilitando extraordinariamente el retroceso de la historia: bien hacia la literatura, exacerbando la subjetividad del historiador, bien hacia un nuevo presentismo sin pretensiones de cientificidad, que opone el compromiso social del historiador a su tarea como investigador.

La dudas prácticas del historiador sobre la vieja objetividad, sus certezas sobre el relativismo del conocimiento histórico, que en realidad lo aproximan a la última filosofía de la ciencia, son paradójicamente percibidas por la comunidad de historiadores -impregnada de positivismo- como un alejamiento de las ciencias naturales, como una vuelta a las humanidades clásicas, con lo que se hace tabla rasa de avances fun- 
damentales de la historiografía del siglo XX. La contradicción se resuelve fácilmente - en teoría, porque es muy difícil trabajar guiados por conceptos relativos - reformulando la ciencia histórica de acuerdo con los últimos avances epistemológicos de las ciencias sociales y, singularmente, de las ciencias naturales.

\section{4}

La redefinición de la historia como ciencia y la nueva física.

¿El concepto de historia debe cambiar al mudar el concepto científico de la realidad? Pensamos que sí. El siglo XX ha supuesto el fin de la mecánica newtoniana a manos de la física cuántica y de la teoría de la relatividad, sin embargo el objetivismo y el absolutismo de la vieja mecánica ha seguido condicionando largamente la joven ciencia histórica. El principio de indeterminación (Heisenberg), el principio de complementaridad (Born), la complejidad y el caos, reintroducen el sujeto en el proceso, y el resultado, de la investigación y relativizan de tal manera la verdad científica, que dejan en evidencia todas las prevenciones de los historiadores, y de otros científicos sociales, hacia el peso de la subjetividad en sus obras. El acercamiento real entre las ciencias de la naturaleza y las ciencias sociales (y entre las ciencias físicas y las humanidades), ahora mucho más compatibles que a principios de siglo, ha sido por el momento más reconocido por los científicos "duros" (el éxito del objetivismo relativo de Kuhn se explica también por ello) que por los humanistas que desde los tiempos del positivismo (Comte) buscaron, y encontraron, en las ciencias de la naturaleza, una referencia epistemológica y metodólogica científica segura.

A finales de siglo se impone un concepto de ciencia que pone término a la separación positivista objeto/sujeto (M0RIN, 1994), ¿puede la historia permanecer ajena a esta revolución científica, cuando su propia práctica la llevado a concluir que no existe una verdad absoluta al margen del observador actual y del sujeto histórico? La historia es, o puede ser, tan objetiva como la nueva física. La nueva ciencia con sujeto no es menos sino más científica que la vieja ciencia (objetivista) del positivismo. Roto, hace ya tiempo, el consenso historiográfico sobre una definición y una práctica objetivista de nuestra disciplina, sólo se podrá recomponer asimilando los historiadores la nueva racionalidad científica, de signo relativista y transdisciplinar, que va a caracterizar el siglo XXI. La reconstrucción del paradigma común de los historiadores, sin el cual la historia será incapaz de superar el desmigajamiento actual y recobrar su papel en la sociedad, requiere tomar nota de los cambios paradigmáticos en el conjunto de las ciencias sociales, y en la concepción general de la ciencia, dictada ayer como hoy por las ciencias de la naturaleza (prueba de que la ciencia no ha abandonado sus bases de partida materiales, realistas). Conforme la epistemología y la metodología de las ciencias "duras" y "blandas" se aproximan, los consensos paradigmáticos devienen más inclusivos.

\section{5}

La historia de la humanidad no avanza hacia una meta fijada de antemano, pero tampoco tiene vuelta atrás.

El estudio del pasado, a partir de los problemas del presente, es un criterio compartido por los historiadores, que justifica la utilidad social de la historia en la lucha de la humanidad por un futuro mejor. Esta idea ilustrada, ingenua y optimista, del progreso indefinido, según la cual el desarrollo científico-técnico engendra una sucesión de formas sociales cada vez más avanzadas, ha chocado primero con las guerras mundiales y los horrores políticos (Auschwitz, Gulag), y más recientemente con una conciencia generalizada del deterioro irreversible del medio ambiente, y de la evidencia de que el bienestar económico sólo favorece a una minoría de países industrializados y condena al 
resto de la humanidad a la miseria. La religión laica del progreso indefinido ha sufrido su último golpe con la caída de los países del llamado socialismo real, que decían estar construyendo una sociedad final comunista y que ahora buscan en el régimen social prerevolucionario, en el capitalismo, la solución a sus problemas económicos y sociales, sin demasiado éxito por lo demás.

No existe una meta preestablecida de la historia de la humanidad como se creyó durante siglos (el juicio final de la historia providencialista, la democracia liberal de Hegel-Fukuyama, la sociedad sin clases de Marx), igual que no existe una verdad científica fija y permanente. Tampoco está garantizado que la evolución social vaya de peor a mejor al desarrollarse la economía, la ciencia y la técnica. El sujeto de la historia es más libre, y el futuro está más abierto, de lo que podíamos sospechar. Lo cual no quiere decir que el progreso se haya acabado, que la humanidad no deba plantearse ambiciosos objetivos móviles-, que el proyecto de la modernidad haya llegado a su fin, sea porque ya se ha realizado plenamente (Fukuyama), sea porque nunca se va a llevar a cabo (posmodernismo), sea porque nos encaminamos hacia una sombría "Nueva Edad Media" (MINC, 1994).

La historia nos ha enseñado que los sentimientos de confusión e incertidumbre acompañan a los períodos de transición, y que éstos rematan tarde o temprano con la implantación de nuevas realidades (y de nuevos paradigmas). Por otro lado, el único progreso histórico que ha habido es el progreso relativo: ni absoluto ni lineal ni inexorable; medido desde el presente y no desde el futuro (salvo para viajeros del tiempo). Un futuro, pues, abierto a diversas alternativas. Y un pasado que nunca vuelve. Una nueva idea racional - no teleológica - del progreso que seguirá incluyendo rupturas y revoluciones -políticas y sociales, culturales y científicas-, que coloca al sujeto en el centro de la historia, que reconoce el papel movilizador de las utopías pero no las confunde con las ciencias.

\section{6}

Sin el sujeto, del pasado y del presente, no es posible una historia objetiva.

La redefinición de la verdad científica que, incluyendo al sujeto observador, realza la función del historiador en el proceso de la investigación histórica, viene a darle la razón a determinados paradigmas historiográficos del siglo XX, como la historia-problema de Annales o la función clave de la teoría en el materialismo histórico, cuya aplicación ha resultado obstaculizada por la pervivencia de la creencia positivista entre los historiadores. El nuevo concepto de objetividad relativa va incluso epistemológicamente más allá de la vieja historia explicativa, al restaurar el sujeto fuerte como fuente de objetividad (la comunidad científica de Kuhn como factor definitorio de lo que es o no es objetivo), al fundir objeto y sujeto, postulando que no tienen vidas separadas. Corresponde científicamente al historiador, individual y colectivo, trabajar con los datos para explicar e interpretar, para buscar la causa y el sentido de los hechos históricos, para construir teóricamente su objeto e investigar empíricamente, como vienen haciendo los científicos "duros" y muchos científicos sociales. La continuidad de los malos hábitos del positivismo (que hace desaparecer ilusoriamente al sujeto-observador) contradice las aportaciones más audaces e inéditas de los fundadores del paradigma historiográfico del siglo XX, la práctica historiográfica vigente, la recuperación plena de la cientificidad de la historia.

La derivación de la escritura de la historia, desde los años 70, hacia una historia del sujeto mental, antropológico, cultural, y más recientemente hacia una historia del sujeto individual, ha hecho olvidar el sujeto colectivo, social, de la historiografía social angloamericana, relegado en la investigación histórica, a causa de la depresión ideológica pos-1968, primero, y de la "ola conservadora" de los años 80 después, hasta que fue rescatado para el debate 
historiográfico por los revisionistas, desde un punto de vista contrario, y también por la historia inmediata. 1989, es, de nuevo, la fecha clave, el año del Bicentenario de la Revolución Francesa y de las revoluciones democráticas en el Este.

El retorno de la revolución y del protagonismo político de las masas en Europa oriental, entre 1989 y 1991, vivido en directo a través de la televisión en todo el mundo, es el retorno del sujeto fuerte de la historia que la historiografía del viejo paradigma, sea annaliste sea marxista, había finalmente dejado de lado, al compás de la coyuntura intelectual, fiel a una historia económico-social estructural o a una historia de las mentalidades (y sucesores) ajena a la historia social (BARROS, 1993).

Esta emergencia conjunta del sujeto fuerte de la nueva epistemología científica y del sujeto fuerte de la historia reciente, no es casual, avisa de que estamos entrando en la era del pos-posmodernismo, anuncia las pre-condiciones para una nueva ilustración. ¿Qué vincula la revalorización colectiva del investigador, de una parte, y del agente histórico, por la otra? La respuesta está en otro punto incumplido del programa annaliste-marxista, la "historia humana" de Bloch y de Gramsci, los hombres haciendo y decidiendo su propia historia, tanto la historia de la ciencia como la historia de los hechos.

Contemplar el sujeto y el objeto de la historia como una misma realidad, es un principio fácil de enunciar pero difícil de aplicar, según los esquemas metodológicos y ontológicos heredados. Todo un reto para los historiadores del futuro.

\section{7}

De la determinación económica simple a la determinación global y compleja, concreta y revisable, de los hechos históricos.

El paradigma objetivista y estructural en activo según Kuhn, ningún paradigma deja de estar vigente hasta que es plenamente sustituido- ha primado el determinismo de la economía, incluso de la geografía, cuando se trata de explicar los hechos históricos, en detrimento de la causalidad subjetiva de la lucha social, orillando otras dimensiones que condicionan asimismo la realidad pasada como la mentalidad y la cultura, la política y el poder, los individuos y las instituciones; determinaciones con las cuales el historiador se encuentra todos los días en sus investigaciones.

La reacción subjetivista contra la prioridad de la historia económica, infraestructural, ha llevado -aunque no siempre-, siguiendo la ley del péndulo, a subrayar la indeterminación de los acontecimientos históricos. Al punto que la historia sería el reino de la contingencia absoluta: un sujeto sin objeto. Así, en un primer momento, la historiografía se desinteresó por la investigación de las causas y de las explicaciones, para negar, más adelante, la posibilidad de conocerlas, al tiempo que volvían los enfoques más tradicionales de la historia y se renovaba otra idea de origen neopositivista: la imposibilidad de aprehender la realidad más allá del discurso (el linguistic turn en su versión más radical).

Nuestra propuesta es superar la polémica determinación/indeterminación llevando a cabo "un análisis concreto de cada situación histórica concreta" con el fin de averiguar, sin rígidas posiciones previas, el grado posible de determinación de un hecho histórico que, como sabemos, depende de las fuentes conservadas, los métodos de investigación, los conocimientos no basados en fuentes, las hipótesis y teorías que utilice el historiador. El resultado es, obviamente, revisable en la medida en que los factores subjetivos de la investigación varíen.

La búsqueda prioritaria de las causas de la historia en su base material, se ha revelado como un enfoque claramente insuficiente, y en ocasiones erróneo. Toda metodología no reduccionista ha de perseguir, pues, la determinación global de los hechos históricos, más allá de los esquemas simplificadores y sepa- 
radores (objeto/sujeto, base/superestructura, economía/ política/cultura) propios del impugnado paradigma objetivista, economicista y estructuralista. La investigación específica nos dirá, en cada caso, el grado de complejidad de la combinación de las determinaciones.

La realidad histórica suele ser más compleja que nuestras metáforas mecánicas, la imposición de éstas nos aleja, en consecuencia, del objeto de estudio; cierto, pero no siempre es así, los esquemas simples pueden hacer plausible en algunos casos una descripción, incluso una explicación, toda vez que la complejidad incluye la simplicidad. Así es como mantiene cierta vigencia la determinación económica de la realidad social, política y cultural, no pocas veces demostrada por la historia y otras ciencias sociales en investigaciones concretas. El problema por resolver, en cada caso, es cómo articular globalmente la economía con las restantes dimensiones, que, además de estar en interacción con ella, viven en su interior: la política y la mentalidad también forman parte de la vida económica y material, y viceversa, de ahí la invariable incapacidad de la metáfora rígida del edificio de tres plantas (economía/política/cultura) para comprender cabalmente, y aun para describir correctamente, la mayor parte de las veces, el mundo pasado. La determinación económica es también, habitualmente, una determinación global y compleja.

\section{8}

Lo que decide que un tema de investigación o un género historiográfico sea válido o no, es la aportación del historiador: los problemas planteados, los métodos aplicados, los resultados obtenidos.

El paradigma objetivista atribuyó al objeto, al tema de investigación, una función excesiva, incluso "mágica", en la legitimación de la cientificidad o de la utilidad social de una obra de historia. Las grandes innovaciones historiográficas del siglo XX fueron, en primer lugar, innovaciones temáticas. En cada época historiográfica se privilegió una forma de historia. A la historia política siguió la historia económica-social, y a ésta la historia desde el sujeto (mentalidades, antropología histórica, nueva historia cultural), cerrándose el círculo, y el siglo, con la vuelta de la historia política (en bastantes casos con nuevos enfoques). En general, se han obtenido buenos resultados en cada uno de estos géneros temáticos de la historia, bajo la influencia de las correspondientes ciencias sociales: ciencia política, psicología, antropología, sociología, economía, etc. Ya no vale primar o descalificar a priori, sin antes analizar los problemas planteados, los métodos aplicados y los resultados obtenidos, un tema o un género historiográfico (SAMUEL, 1984, p. 64). La mayor parte de los campos historiográficos que en este fin de siglo, a modo de recapitulación y resumen, están encima de la mesa del historiador, han obtenido ya su carta de naturaleza en el mundo de la historia profesional.

Esta amplitud de objetos sin precedentes es una conquista irreversible de la historiografía contemporánea. El ensanchamiento del tipo de fuentes utilizadas (de la documentación escrita a "todos los documentos", según la expresión de Febvre), fue seguido de tal alargamiento del territorio temático del historiador, que se hace, ahora, dificultoso descubrir nuevas parcelas historiográficas, $y$, si bien el presente -y el futuro- van a continuar sugiriendo nuevas materias de estudio, debemos de concluir que el centro de gravedad de la renovación historiográfica se desplaza hacia enfoques más metodológicos y teóricos.

El primer problema teórico por resolver con espíritu innovador es, justamente, el de la fragmentación de la historia en múltiples objetos desconectados entre sí. La incompetencia de la historiografía del siglo XX para ofrecer una explicación de conjunto, unitaria, del pasado de los hombres, ha quedado patente donde sus avances son más manifiestos: la diversificación temática. La paradoja está en que bajo la variedad en aumento de especialidades y subespe- 
cialidades, subyace de alguna forma la búsqueda de una historia total (entendida como horizonte utópico), la idea de que hay que estudiarlo "todo"; el precio pagado fue quedarnos sin lo fundamental: una investigación global de la historia de los hechos, períodos temporales o civilizaciones del pasado.

\section{9}

\section{De la necesaria pluralidad de la innovación metodológica}

El paradigma historiográfico del siglo XXI está obligado a ser más global y transnacional que el paradigma historiográfico del siglo XX. Una mayor interrelación entre cultivadores de distintos tipos de historia, y entre historiografías nacionales, acabaría con ese prejuicio académico de descalificar las vías de renovación historiográfica ajenas a la propia. No se trata solamente de predicar la tolerancia -virtud intelectual cuya ausencia tendría que encender todas las señales de alarma-, la cuestión es que la pluralidad innovadora en el método es, en este momento, imprescindible para la recomposición del paradigma común de los historiadores, y para avanzar de nuevo, desde las múltiples variedades historiográficas, hacia un terreno común, única forma de conseguir que la disciplina reconstruya finalmente sus señas unitarias de identidad.

En tiempos de la hegemonía objetivista, la metodología cuantitativista venía siendo el paradigma de la exactitud y de la cientificidad; ahora mismo, el retorno de los métodos cualitativos, corre el peligro de llevarnos al otro extremo; lo más avanzado sería, desde luego, una combinación de métodos cualitativos y cuantitativos si el tema, las preguntas y las fuentes, lo exigen y/o lo facilitan.

El método cualitativo por excelencia de los historiadores, es la narración. Denostada como paradig- ma de una historia tradicional tachada -no sin razones- de superficial, descriptiva y acontecimental, por la nueva historia annaliste-marxista, la historia narrativa vuelve, a mediados de los años 70, como índice de la crisis de la historia científica (Stone), siendo posteriormente asimilada por ésta a marchas forzadas. Autores representativos como Georges Lefebvre y Jerzy Topolsky han defendido, hace ya tiempo, una historia-relato explicativa (KUHN, 1983, p.32-33, 39), más allá de la infrahistoria vulgarizadora, y filósofos como Paul Ricoeur han argumentado, en la misma dirección, que toda historia es relato, incluido la Méditerranée de Fernand Braudel, obra paradigmática de la macrohistoria estructural de larga duración.

La verdad es que, prejuicios aparte, todos los historiadores empleamos de algún modo el relato, la conexión narrativa, para dar forma a nuestras investigaciones, ¿cuántas veces las conclusiones no adoptan su forma final hasta el momento de la redacción? La buena o la mala historia, tanto si nos referimos a la calidad como a la orientación, depende más del fondo que de la forma: es posible una historia narrativa no positivista, global y socialmente útil. No necesariamente una forma narrativa ha de conllevar un trasfondo de historia conservadora.

Una de las últimas vías de renovación historiográfica del paradigma objetivista, economicista y estructural, que no renuncia a la historia explicativa ni al relato histórico, está en la reducción de la escala de observación: la microhistoria (algo muy distinto de la vieja historia local). Pero, paralelamente, mediante la historia comparada -antiguo proyecto crítico alentado por Bloch, que no llegó a formar parte del paradigma común de la posguerra-, se nos propone otra manera de hacer macrohistoria. La conexión entre la microhistoria y una macrohistoria renovada, está por realizarse, así como, en general, las investigaciones históricas verdaderamente globales (más allá de la caricatura mecanicista de los tres niveles). El cambio de escala, micro/macro, la articulación de 
los espacios (y de los tiempos), pueden ser excelentes caminos para la globalización metodológica y teórica de la historia, para la rectificación de uno de los aspectos más negativos de la rica -por complementaria- evolución de la historiografía finisecular: la fragmentación de los objetos y de los métodos.

\section{0}

El éxito del nuevo paradigma dependerá de su capacidad para generar y aplicar estrategias globales de investigación.

La mayor anomalía con que se ha topado el consenso historiográfico del siglo XX, es la imposibilidad de llevar a la práctica el principio de historia total. Citada ritualmente por los historiadores, se ha ido convirtiendo en el paradigma compartido más abstracto: según se ha alejado de la práctica historiográfica, la historia total ha devenido más absoluta e inalcanzable, en suma, más idealista. Cortar este círculo vicioso es condición sine qua non para salir definitivamente de la actual crisis de crecimiento y desagregación de la historia.

Cada vez sabemos más de menos cosas. Esta tendencia general del conocimiento científico, junto con el fracaso de la historia total, ha encauzado la creatividad de los historiadores hacia una creciente especialización. Aunque, últimamente, emerge con gran fuerza la tendencia contraria, hacia una convergencia disciplinar y global (la investigación por parte de filósofos y físicos de una teoría unificada de las fuerzas físicas, es un notorio ejemplo), que también se hace sentir en la historia profesional. Muchas de las aportaciones recientes más novedosas son, si nos fijamos bien, fruto del mestizaje de géneros y metodologías. El contexto presente de transición paradigmática nos ofrece, juntamente, el problema y la solución.

Se trata de dar la vuelta a la historia total, poniéndola sobre los pies, transformando su contenido (y tal vez su nombre). Hay que llevar este viejo concepto paradigmático de lo absoluto a lo relativo, de la idea a la práctica, de la teoría a la metodología, de la certeza a la experimentación, del punto de llegada al punto de partida de la investigación; para lo cual es preciso promover síntesis de géneros historiográficos, convergencias de líneas de trabajo, aproximaciones globales, enfoques de conjunto, es decir, estrategias globales de investigación. Todo aquello que el fracasado paradigma compartido de la historia total ni ha impulsado ni ha permitido impulsar, a lo largo del siglo XX, salvo valiosos ejemplos que quedaron aislados, y que nunca fueron más que aproximaciones globales.

En este grandioso archipiélago en que se ha ido convirtiendo la historia del siglo XX, lo que faltan son puentes, vías de comunicación, y otras conexiones interhistóricas, que hagan posible juntar islas para hacer continentes historiográficos, que nos hagan olvidar la espera pasiva del advenimiento de una historia total sacralizada. La puesta en práctica, previo proceso de secularización y relativización, de una nueva noción de historia global, implicará un esfuerzo continuado de renovación historiográfica, que ha de atravesar la superespecialización académica. Sobre la base de una experiencia colectiva de aproximaciones globales al pasado humano, es menester reconstruir teóricamente un concepto de "totalidad" histórica liberado de toda carcasa kantiana, y de las divisorias, positivistas y mecanicistas, del tipo objeto/sujeto o infra/supraestructura, un concepto renovado y adecuado, por tanto, al nuevo paradigma científico general, más relativo, ergo más verdadero.

La historia como disciplina científica no puede permitirse el lujo de renunciar a la comprensión global del pasado. El papel de la historia en la sociedad, en la educación y en la investigación, es inversamente proporcional a su desmigajamiento disciplinar. Una piedra de toque del nuevo paradigma historiográfico será, en conclusión, su aptitud para crear y aplicar estrategias globales de investigación, y de divulgación, de los hechos de la historia. 
11

Para reforzar la cooperación de la historia con otras ciencias, es preciso avanzar en su unificación interna como ciencia de los hombres en el tiempo.

No se puede prescindir de la interdisciplinaridad para discernir la potencia innovadora del paradigma historiográfico del siglo XX. De la geografía, la economía, la demografía, la sociología, la antropología, la psicología, la ciencia política, han salido muchos de los temas y métodos que han aplicado con éxito los nuevos historiadores de Annales y del marxismo occidental, sin por ello dejar de moverse en un paradigma historiográfico común (la interdisciplinaridad es uno de sus componentes más relevantes). Y algo parecido se podría decir de las mencionadas disciplinas, que han acudido a la historia para aprehender su dimensión temporal, engendrando subdisciplinas mixtas, a menudo con investigadores de doble procedencia: geografía histórica, historia económica, demografía histórica, sociología histórica, antropología histórica, psicología histórica, nueva historia política. La necesidad que hemos planteado, al inicio de este ensayo historiográfico, de que los historiadores vayan al encuentro de la historia/filosofía de la ciencia, prueba que tampoco en el terreno de la epistemología histórica, y de la relación con las ciencias físicas, la historia puede prescindir del diálogo inter y transdisciplinar, más bien ha de intensificarlo, como un signo de los tiempos, al igual que las restantes ciencias naturales y sociales.

Mantener y acrecentar la cooperación de la historia con las ciencias sociales (y aun naturales) es, por consiguiente, inexcusable, para luchar contra la marginación de la historia como disciplina académica y social. Los rápidos cambios de denominación, de lo interdisciplinar (cooperar) a lo pluridisciplinar (converger), de lo pluridisciplinar a lo transdisciplinar (atravesar y transcender), ponen en evidencia una actividad científica que busca independizarse de los clásicos compartimentos académicos, sin por ello caer en la vieja ilusión positivista de una "ciencia unificada".

La historia no es insensible al clima transdisciplinar, consecuencia directa del auge finisecular del conocimiento científico, puro y aplicado. Así, la revista Annaleselige como eje de su tournant critique (1989), la alianza renovada de la historia con las ciencias sociales, y recompone su comité de dirección, que recupera así el perfil inter y pluridisciplinar que tuvo en sus orígenes, incorporando a un grupo de jóvenes no historiadores. La nueva licenciatura de humanidades en España ilustra, en el terreno de la educación universitaria, esta propensión general al reencuentro de las disciplinas, contrapunto de las tendencias centrífugas de los años 80 (que todavía siguen actuando en el interior de cada disciplina).

En los años 80, la coincidencia de la dispersión, y del decaimiento, del paradigma historiográfico del siglo XX, con un incremento de la colaboración con las disciplinas vecinas, generó en algunos historiadores una reacción contra el peligro de la dilución de la historia en otras ciencias sociales, que condujo a los más radicales a rechazar la interdisciplinaridad, e incluso la definición de la historia como ciencia. El intercambio desigual historia-ciencias sociales no se resuelve, sin embargo, con la involución de la historia, retrocediendo a una historia pre-paradigmática de corte tradicional; se resuelve atacando la raíz del problema. La historia es débil frente a otras disciplinas, porque éstas han estado, y están, mucho más preocupadas por la teoría (la sociología, la antropología o la crítica literaria), y ello les ha permitido actuar de modo "imperialista" en el interior del sistema de las ciencias sociales y humanas, exportando métodos y conceptos, problemas y teorías, con intenciones asimiladoras. Este problema de la historia es tan antiguo como la propia disciplina, y sólo tiene una solución: que los historiadores desarrollemos las consecuencias teóricas y metodológicas de las investigaciones históricas, con los ojos puestos en el conjunto de problemas 
que tienen las ciencias y las sociedades actuales. Es tan sencillo como dejar de centrar la crítica en los demás (en sus teorías) y ser más autocríticos (desarrollando nuestras propias reflexiones). Hemos llegado a tal extremo que la interdisciplinaridad que venimos practicando ya no podrá progresar más, si antes la historia profesional no recobra un mínimo de unidad interna y de globalidad en su quehacer.

Nada hace más vulnerable a la historia, en el conjunto de las ciencias, que su fragmentación interna. La interdisciplinaridad bien entendida habría de empezar, pues, por nosotros mismos. Una aportación mayor de la historia a las ciencias sociales y humanas, con las que colabora habitualmente -especialmente, en las investigaciones de vanguardia-, requeriría un reencuentro de las múltiples subdisciplinas históricas (de origen académico, temático y/o metodológico) en un terreno común, dicho con otras palabras, una recomposición del paradigma común de los historiadores que no oponga la imprescindible cooperación y convergencia con las ciencias sociales con la, si cabe más urgente, cooperación y convergencia entre las ramas sucesivamente desgajadas del tronco de la historia. Esta suerte de interhistoria que propugnamos, en el marco de la colaboración interdiciplinar historia-ciencias sociales, entraña una mayor preocupación de los historiadores, de todas los campos, por la metodología histórica, por la historiografía, por la teoría de la historia, en definitiva, por el acervo común de la historia. Las demandas crecientes de interdisciplinaridad solamente pueden ser satisfechas por una disciplina histórica consciente de su unidad y de su irreductible singularidad.

\section{2}

El futuro de la historia está condicionado por lo que se preocupe la historia por el futuro.

Siguiendo a la Ilustración, que confiaba en la razón para cambiar el mundo, y conseguir de esta ma- nera el bienestar de la humanidad, la historiografía predominante en el siglo XX se autodesignó como objetivo: estudiar el pasado a fin de comprender el presente, y de construir un futuro mejor. El materialismo histórico insistió más en la contribución de la historia a un proyecto de trasformación social, cara a un futuro que se sabía socialista, y la escuela de Annales puso más el acento en la conexión epistemológica pasado-presente (comprender el presente por el pasado, comprender el pasado por el presente, escribió Bloch), participando todos de la creencia general en la utilidad social de la nueva ciencia histórica.

La línea de progreso con que los miembros de la comunidad historiográfica, y en general los científicos sociales, unían el pasado con el presente y el futuro, se ha roto con los hechos de 1989, al iniciarse las transiciones europeo-orientales del socialismo real al capitalismo, al entrar por ello conjuntamente en crisis todas las vías de progreso histórico-social de origen ilustrado, previamente socavadas por los nocivos efectos que éstas causaron, a lo largo del siglo XX, en la supervivencia de la especie y de la naturaleza. Y lo que es peor: la historia científica no lo advirtió.

En la medida en que la evolución progresiva hacia la felicidad humana no está asegurada, la historia pierde interés público. Se empuja de este modo al historiador a los márgenes de la sociedad; pronto se pueden volver actuales las críticas, de hace cincuenta años, de los artífices de la revolución historiográfica del siglo XX a los historiadores-anticuarios, ajenos a la vida y a la actualidad (Bloch). El desencanto hacia el presente conduce a buscar refugio en el pasado de dos maneras: la ficción, desde el punto de vista del público (auge de la novela histórica), y la academia, desde el punto de vista de los investigadores (erudición). Para ambos viajes, se quiere "liberar" a la historia de la carga que supone su definición como ciencia preocupada -al igual que las restantes ciencias de la sociedad y de la naturaleza- por el presente y por el porvenir de los hombres. 
Pero, mientras el posmodernismo ambiental lleva a los historiadores a la subalternidad, en los debates intelectuales que tratan de sacar conclusiones de los acontecimientos traumáticos de 1989-1991, se usan profusamente los datos de la historia, y de la filosofía de la historia, para arrojar luz y polémica sobre el confuso futuro de la humanidad. Es el caso de las controversias mundiales principiadas por Francis Fukuyama en The End of History? (verano de 1989), y por Samuel P. Huntington en The clash of civilizations (1993). El segundo ha desmentido brillantemente la finalista "paz capitalista y liberal" del primero, augurando una inminente guerra mundial de los fundamentalismos religiosos. No siempre son ensayistas -filósofos políticos en los dos casos citados- quienes acuden a la historia para intervenir en el futuro inmediato, también lo hicieron historiadores como Paul Kennedy que, en The Rise and Fall of Great Powers (1987), dedicó siete capítulos a analizar, durante cinco siglos, el auge y la caída de las potencias nacionales de cada época, para concluir con un capítulo, titulado "Hacia el siglo XXI", donde sugiere las "perspectivas más probables" de evolución de cada gobierno y del sistema de las grandes potencias en su conjunto.

Nos hallamos ante referencias al pasado y análisis históricos que pretenden incidir en el presente... a través del futuro, que es lo que realmente inquieta a los hombres de hoy. Se tiende, consiguientemente, a sustituir el viejo paradigma pasado/presente/futuro por otra formulación, pasado/futuro/presente, en la que pasa a primer plano aquello que está por venir. Frente al nuevo presentismo que nada quiere saber del futuro y que inmoviliza lo que ahora tenemos, frente a las incertidumbres sobre el mundo que nos aguarda a la vuelta del milenio, el intelectual diligente -el optimismo de la inteligencia- rastrea perspectivas alternativas echando mano del pasado, de los conocimientos que tenemos sobre la evolución -o involución- histórica de las sociedades y de las mentalidades.
Antes decíamos que la historia nos tiene que ayudar a vivir mejor, a transformar la sociedad, a emanciparnos, en una palabra, de un presente ominoso, pero hoy han variado dramáticamente los términos del problema, en especial para la nuevas generaciones: lo más abominable no es ya el presente sino la falta de futuro, de cualquier futuro. Se sabe que el desarrollo científico-técnico seguirá medrando hasta dominar todo el globo, pero también se sabe que de sus ventajas, en Occidente, está excluido el llamado Cuarto Mundo, y masas crecientes de jóvenes -muchos de ellos con formación universitaria, cada vez más- que no tendrán jamás acceso al trabajo; en el Sur, los excluidos son países enteros abocados al hambre y la superpoblación; y, por doquier, la naturaleza se rebela contra el galopante dominio productivista, cuestionando el sentido de un desarrollo científico- técnico que, una y otra vez, entra en contradicción con los intereses humanos.

Es tarea de la historia, hoy en día, demostrar que siempre hubo futuros plurales; que nada es seguro, que todo cambia, a veces sorprendentemente; que la humanidad en varios milenios ha resuelto históricamente problemas tanto o más difíciles -y con menos medios- que los que ahora tenemos encima de la mesa. Hay pues futuro, porque hay historia. Además, son futuros alternativos. Hay esperanza porque hay historia. Claro que para hacerlo comprender a los demás, debemos antes convencernos nosotros mismos, abandonando el objetivismo mecanicista, con su secuela de fatalismo y conformismo, para encaminarnos hacia un sujeto histórico más libre (que no ha de olvidar sus condicionamientos), y por lo tanto más fuerte, en el pasado y en el presente.

Pensar históricamente el futuro, es luego transformar el presente, empezando por impedir que se repitan los grandes errores del siglo XX: el fascismo, que rebrota en Italia, y el racismo, en ascenso par tout; el socialismo sin libertad, que se hundió catastróficamente en 1989; el tribalismo, el nacionalismo agresi- 
vo y el fundamentalismo religioso, cuyos mitos e irracionalidades el historiador tiene la obligación de combatir, y que están en el origen de muchas de las guerras que hoy amenazan la paz mundial. Se demanda un nuevo racionalismo, una nueva ilustración, que nos permita seguir progresando, y la historia y los historiadores no podemos permanecer al margen de esa demanda intelectual y social.

Cuando, después de la II Guerra Mundial, se instituyó el paradigma científico de la historia, no era tan necesaria, como lo es ahora, su defensa frente a las disciplinas científico-técnicas, que, en diferente grado y ritmo -según cada país-, desplazan a los saberes históricos y humanísticos de la enseñanza y de la investigación; está en sus inicios un alarmante proceso de desprofesionalización de la historia. De manera que el primer compromiso del historiador preocupado por el futuro, es inquietarse por su propia disciplina: es menester volver a demostrar la utilidad crítica y social de la historia. Para hacer frente al pensamiento tecnocrático, filosóficamente desfasado, pero políticamente activo, hay que distinguir la historia- ciencia de la historia-ficción, y guerrear por la recuperación de la presencia de la historia en el sistema educativo, en los proyectos prioritarios de investigación y en los medios sociales de comunicación. La aldea global que viene, sin la historia y las ciencias humanas, será el futuro de las cosas, jamás el futuro de los hombres.

\section{3}

El historiador del futuro reflexionará sobre metodología, historiografía y teoría de la historia, o no será.

Estuvo muy generalizado desde la epistemología (Piaget, Habermas), la sociología (Durkheim) o el estructuralismo, considerar a la historia como una disciplina no teórica, simple proveedora de datos empíricos para las ciencias sociales y la filosofía. División del trabajo que, aunque nos duela decirlo, el historiador suele aceptar de buen grado, alentado por una tradición empirista de larga duración, originada en el siglo XIX.

Pese a los esfuerzos del materialismo histórico, y de la escuela de Annales, la historiografía contemporánea siguió siendo positivista en un punto capital: el desprecio sincero por la teoría, y en menor medida por la historiografía y la metodología; actividades científicas tenidas por secundarias, y se puede decir que casi inexistentes en la obra de muchos de los historiadores que consideramos consagrados. La comparación no llegó a practicarse (hasta que la sociología histórica la retomó); la historia-problema se abandonó en favor de la innovación temática y la colaboración interdisciplinar; la elaboración teórica estuvo prácticamente ausente. Sólo algunos filósofos se han venido preocupado por la teoría de la historia, generalmente sin considerar las aportaciones de los historiadores, sin relacionar la teoría de la historia con la práctica de la historia, contribuyendo así al vigente diálogo de sordos entre la filosofía y la historia.

Las consecuencias del inductismo y del pragmatismo de los historiadores, de la falta de reflexión sobre la historia que se hace, de la carencia de debate sobre sus métodos, sus hipótesis e sus interpretaciones, las hemos visto ya: fragmentación de temas, métodos y especialidades; retraso y dependencia respecto de otras ciencias sociales; desconexión de una sociedad a la que deberíamos estar ofreciendo, desde la historia: ideas, propuestas y perspectivas a sus problemas.

Este Congreso Internacional A historia a debate, es, no obstante, un vivo ejemplo de que algo está cambiando. El interés de los historiadores por la metodología, la historiografía y la teoría de la historia, crece en este complicado fin de siglo. Tal vez porque "conforme crece la ciencia, disminuye el poder de la evidencia empírica" (LAKATOS, 1983, p. 33), y aumentan unos interrogantes que ninguna otra disciplina, por muy avanzada que esté, nos puede resolver, porque son específicos de la historia. Una historia profesio- 
nal que, en todo caso, aborda con más facilidad la reflexión sobre el método, o sobre la historia de la historia, que la fabricación y el empleo de hipótesis y de tesis, y de síntesis y de generalizaciones, en las investigaciones, a causa, sin duda, de la formación recibida y del fracaso parcial del paradigma marxismo-Annales, ambas cuestiones muy entrelazadas. Sólo la introducción de asignaturas de metodología, historiografía y teoría de la historia, desde los primeros cursos de las licenciaturas de historia, para acostumbrar a los futuros historiadores a la reflexión sobre su materia, permitirá equiparar la historia al resto de las ciencias.

La disyuntiva del historiador del futuro es: o dedicar una parte del tiempo de trabajo a conocer y producir obras de metodología, de historiografía y de teoría histórica, en competencia (y colaboración) con las disciplinas vecinas; o sucumbir definitivamente a la marginalidad en el seno de la ciencia y de la sociedad. Que sea difícil para el historiador alternar el trabajo empírico con el trabajo teórico, no quiere decir que sea una cosa del otro mundo: la mayor parte de las ciencias sociales y humanas vienen practicand, desde hace mucho tiempo, esta combinación teoría/ práctica. Agotada en buena medida la innovación temática, a la historia le queda la metodología, la historiografía y sobre todo la teoría, continente persistentemente ignorado, para seguir progresando y para cumplir con sus responsabilidades científicas y sociales.

Una mayor reflexión sobre lo que hace el historiador redundará en un alza del nivel de la investigación histórica, en una mayor compresión global del pasado, en una mejor interrelación con las restantes ciencias (intercambio igual), en un incremento de la contribución directa de los historiadores a la teoría de la historia (y por consiguiente de la sociedad) que demandan los acontecimientos del siglo XX y los interrogantes del siglo XXI. Solía decirse que si un historiador hacía teoría dejaba de serlo. Si no se desmiente este lugar común, la historia nunca superará la subalternidad respecto de otras ciencias sociales, no sobrevivirá al siglo XX como disciplina científica tal como la hemos conocido, sobre todo, tal como la hemos querido.

\section{4}

\section{Por una historia continuamente a debate.}

De entrada, el debate no es un uso académico. Los nuevos historiadores, annalistes y también marxistas, han reproducido el sistema vertical de la tradición universitaria que transmite el saber jerárquicamente; las lecturas de las tesis doctorales son un buen ejemplo de lo que queremos decir. Sin embargo, en sus orígenes revolucionarios, Annales predicaba que el debate y la heterodoxia eran consustanciales con la definición científica de la historia: "en el origen de toda adquisición científica existe el no-conformismo. Los progresos de la ciencia son fruto de la discordia. De la misma manera que las religiones se refuerzan con la herejía de que se alimentan" (FEBVRE, 1975, p.34). Es preciso recuperar este espíritu inconformista, crítico, resucitar la historia-debate, para superar la crisis finisecular de la historia, y también para, después de ello, alimentar el nuevo paradigma común, aprendiendo de la historiografía pasada.

A la comunidad de historiadores le toca decidir sobre los problemas historiográficos que tenemos y sus posibles soluciones, pero ¿cómo hacerlo si las dificultades y las alternativas no se exponen libre y polémicamente? Sin potenciar el debate, es imposible llegar a nuevos consensos, y las situaciones críticas -enseña la historia- pueden llegar a pudrirse.

Kuhn ha planteado que, en toda ciencia, el cambio de paradigmas -las crisis, las revoluciones científicas- lleva aparejado un debate (KUHN, 1975, p.87; 1979, p.22; 1983, p.297), pero como no se pueden estar replanteando eternamente los fundamentos de 
una disciplina, en los períodos que él llama de ciencia normal, cede la rivalidad de teorías, dejan de explicitarse reglas y presupuestos, disminuye el interés por la teoría, y se discuten solamente aquellas cuestiones que no son principales para la práctica de los investigadores (KUHN, 1975, p. 143, 276-277; 1979, p.9, 19, 21). El mismo Kuhn excluye, por descontado, a las ciencias humanas y sociales, de estos períodos "normales" de ciencia sin debate, reconociendo la función creadora de la confrontación y de la crítica permanente, por ejemplo, en filosofía y en historia (KUHN, 1983, p.34), en lo cual, por cierto, coincide con su adversario Popper (KUHN, 1983, p.296). Aun en las ciencias naturales, treinta años después de las obras principales de Kuhn, tenemos muy serías dudas de que sea aplicable, en lo relativo a la controversia, una separación tan neta entre ciencia normal y ciencia extraordinaria; la crítica interna que toda disciplina viva tendría que institucionalizar, es hoy, además, una obligación, considerando la velocidad con que los descubrimientos científicos se suceden, al menos en algunas ciencias.

En el caso de la ciencia histórica, la perentoriedad de un debate constante, la historia-debate como parte del paradigma por establecer, más allá por tanto de la urgencia de la crisis actual, surge de la expansión de la historia como disciplina, de su peculiaridad como ciencia de un pasado humano, que es interrogado e interpretado desde un presente y desde un futuro que son móviles -y hacen móvil al pasado investigado-, y de la propia experiencia de los historiadores durante los últimos veinte años. La falta de un debate explícito y suficientemente centrado ha prolongado excesivamente una deplorable situación de equilibrio inestable, donde lo nuevo no acaba de imponerse y lo viejo no acaba de desaparecer, donde las posiciones se polarizan o se dispersan, sin que nadie efectúe y divulgue síntesis sucesivas que aseguren la reformulación del consenso. El desfase entre la práctica plural de los historiadores (fragmenta- da pero fructífera, innovadora pero recuperadora de viejos géneros) y una teoría, que por inercia sigue remitiendo al paradigma marxista-annaliste del siglo $\mathrm{XX}$, es más que evidente. Para corregirlo, hay que debatir a tumba abierta, reconociendo la crisis -sin engañarnos a nosotros mismos con jeremiadas o con dosis extremas de voluntarismo-, y llegar a conclusiones que nos ubiquen en nuevas coordenadas paradigmáticas. Lo cual supone la reimplantación de hábitos de tolerancia hacia las posiciones contrarias, cuyas aportaciones a la recomposición de un paradigma común hay que saber aceptar. La dinámica de rivalidad y cooperación, entre la escuela de Annales y el materialismo histórico, que ha hecho viable la victoria del paradigma historiográfico del siglo XX, es la mejor prueba de lo que estamos defendiendo: las divergencias fructíferas son una elemental exigencia de una historiografía sana.

\section{5}

La madurez de un paradigma está en las escuelas que lo animan.

La crisis de crecimiento y, juntamente, paradigmática, por la que atravesó la historiografía mundial en los años 80, desagregó su paradigma común y provocó tendencias centrífugas que disgregaron sus componentes, divorciando las historiografías nacionales y las grandes escuelas del siglo XX.

Junto con el debilitamiento y el cuestionamiento de los paradigmas compartidos que les concedían funcionalidad, relaciones mutuas y autoridad conjunta, la escuela de Annales y la escuela marxista de historia social, siguiendo -y animando- la tónica general, se diversificaron internamente durante la última década, fueron objeto de una acerba crítica externa e interna (BARROS, 1991a), y se distanciaron entre sí, de suerte que hoy muy pocos mantienen, o aceptan, que sigan siendo escuelas historiográficas con cabezas de fila, programas unificados de investigación, disciplina y órganos de expresión. 
En la dirección colegiada de la revista Annales reina en la actualidad una diversidad -rica- de líneas historiográficas, que tienen su punto de encuentro en la relación con el exterior: la interdisciplinaridad. Esta falta de nexo interno, es más evidente conforme ampliamos el círculo al Centre de Recherches Historiques de la École des Hautes Études en Sciences Sociales, y, por último, a las universidades francesas. El fraccionamiento de la escuela de Annales, nacida en 1929, no es más que una consecuencia -y una causade la dispersión general de la historioa en el último tercio del siglo, que afecta también, sobremanera, a los historiadores próximos al marxismo. El nacimiento en 1976 de History Workshop, las polémicas entre E. P. Thompson y Perry Anderson -y otros- sobre el estructuralismo (1978-1980), y entre Lawrence Stone y Eric J. Hobsbawm sobre el retorno de la narrativa (1979-1980), marcan las tensiones de una diversificación que pronto se convertirá en críticas a la historia social que representa Past and Present J. OBELKEVICH, "Past and Present. Marxisme et histoire en Grande-Bretagne depuis la guerre", Le Débat, nº 17, 1981, p. 106-107, 111. Al evitar la historia política evitan todo lo esencial para el desarrollo de la sociedad humana, a pesar de sus pretensiones radicales, Elisabeth FOX, Eugene GENOVESE, "La crisis política de la historia social. La lucha de clases como objeto y como sujeto", Historia Social, 1, 1988, p.106; otros pueden ver en este marxismo político la continuidad de la historiografía anglosajona tradicional, empirista y pragmática. Julián CASANOVA, La historia social y los historiadores, Barcelona, 1991, p.125; resalta este autor como una segunda generación de historiadores marxistas británicos y norteamericanos quiere tomar el relevo de una historia social que se hace vieja. ídem, p.126., revista que, a fin de cuentas, nunca tuvo un carácter de escuela tan delimitado como Annales. En ambos casos, el resultado es el mismo, un big bang inicial y una expansión posterior que terminó por fragmentar $\mathrm{y}$ enfrentar a las partes.
Se ha generalizado, en total, entre los historiadores, la creencia de que las grandes escuelas del siglo XX son ya cosa del pasado, tradiciones de referencia (CHARTIER, 1993, p.39) pero ya no escuelas activas (ANÓNIMO, 1989, p.1317). La mejor referencia que tenemos de una tradición historiográfica no organizada como escuela, es el positivismo. El marxismo y Annales, en este momento, en los años 90, se parecen más a las viejas tradiciones pre-paradigmáticas, suerte de tendencias difusas, que a verdaderas escuelas de pensamiento y acción historiográfica. Es curioso observar como, a medida que la rivalidad se impone a la cooperación entre ambas escuelas, muy pocos se dan cuenta -de ahí la importancia de las dos primeras tesis de nuestra propuesta- de que las crisis sufridas por la historiografía marxista y por Annales, guardan una íntima relación, van paralelas en su fase final y remiten ambas a una crisis general del paradigma común, a su vez influida por los cambios del paradigma científico global, y por las trasformaciones socioculturales y políticas finiseculares.

El decaimiento del paradigma común y de las grandes escuelas que lo sostenían, en un contexto de desarrollo de la historiografía mundial, ha engendrado fenómenos hasta cierto punto contradictorios: 1) El individualismo historiográfico, alentado por la necesidad y/o el gusto por el currículum académico, y por el auge del individualismo como mentalidad colectiva en los años 80.2) Un mayor peso de las tradiciones historiográficas "naturales", que identifican a los investigadores por encima de cualquier anterior referencia paradigmática o de escuela: a) el área de conocimiento, conforme a los esquemas convencionales de clasificación universitaria (en Europa occidental: historia antigua, medieval, moderna y contemporánea); y b) las historiografías nacionales. 3) La tendencia a la mundialización de la historiografía, sobre la base de una intensificación de los contactos internacionales; proceso de interrelación que afecta a un minoría, pero que tiene a su favor la aceleración 
del mundo presente hacia la "aldea global", en todos los ámbitos de la vida.

La revitalización de la historia como ciencia social reclama un rol activo de la comunidad de historiadores alrededor de un programa historiográfico, reclama proyectos colectivos más allá de los marcos académicos y también nacionales -por supuesto, ambos ineludibles-, reclama combates por la historia del estilo de las escuelas historiográficas que hemos heredado. Por mucho que la realidad se está encargado de rebasar ampliamente a las viejas escuelas, el "espíritu de escuela" historiográfica, tan específico del siglo XX, es, aquí y ahora, más necesario que nunca.

Hemos escrito "escuelas" en plural y no "escuela" en singular, porque creemos que, ni en el pasado ni en el futuro, "paradigma común" equivale equivaldrá- a "escuela única" de teoría y práctica historiográficas. El tono crítico y autocrítico, la historia-debate, la vitalidad de un paradigma, están, en una palabra, mejor garantizados con una diversidad de escuelas, grandes y pequeñas, internacionales y nacionales, interdisciplinares y disciplinares... La diversidad académica, nacional, ideológica, generacional, de la comunidad de historiadores -o de otra ciencia social- obliga, pues, a combinar eficazmente pluralidad con consenso.

La primera tarea de la historiografía del siglo XXI es reformular y revitalizar los aspectos válidos -unos ya aplicados, otros todavía inéditos- de las grandes escuelas del siglo XX, lo que implica nuevos focos de intervención historiográfica, dentro y/o fuera de dichas tradiciones, que además de buscar la divergencia procuren la convergencia, aquellas síntesis sucesivas que nos permitan avanzar y salir del pantano de la transición paradigmática. Teniendo muy claro que el paradigma común que viene no será, no está siendo ya, una repetición del paradigma común, de raíz annaliste-marxista, del siglo XX.

Para "asimilarlo a lo nuevo, lo antiguo debe ser revalorado y reordenado" (KUHN, 1983, p.249). Es menester un balance finisecular de la historiografía annaliste y marxista ( $\sin$ omitir el positivismo), por separado y conjuntamente, que tome nota de los éxitos y de los fracasos, de las limitaciones internas y externas, de los objetivos realizados y de los puntos incumplidos. La mejor aportación de las escuelas del siglo XX al nuevo consenso historiográfico, urgido por nuevas necesidades científicas y sociales, sería una autocrítica que, incidiendo en la renovación y el abandono de sus partes muertas, no se prive de defender sus aspectos más actuales, o más imprescindibles. Seamos radicales en ambos sentidos, en la innovación y en la vigencia. Enfrentémonos al pensamiento simplificador que veda llevar a cabo en paralelo las dos operaciones, y al posmodernismo que proporciona la crítica pero nos niega la síntesis, esa tensión esencial entre tradición y cambio, entre pensamiento divergente y pensamiento convergente (KUHN, 1983, p.249), que es la base, en resumidas cuentas, del progreso científico y social.

La revista Annales ha dado ejemplo lanzando a finales de 1989 un tournant critique (BARROS, 1991b, p.193-197) que, cuatro años después, ofrece unos frutos restringidos -ilustración de las grandes dificultades existentes para promover el cambio desde el centro de las grandes tradiciones-, esto es, una significativa renovación generacional, pero muy pocas propuestas programáticas. La escasez de debate en las páginas de la revista y la desconexión francesa con la evolución reciente de la historiografía marxista, principalmente anglosajona, han coadyuvado al restringido eco del tournant critique de Annales, que señala, así y todo, una nueva etapa para la corriente fundada por Bloch y Febvre, cuyo perfil final está todavía por decidir.

Desde la historiografía marxista no se ha intentado, hasta ahora, nada parecido. Hay actitudes reinvidicativas y defensivas, y también otras realistas y severamente autocríticas, ambas útiles e irremediables, pero teñidas de pesimismo, faltas de alternati- 
vas cara el futuro. El mayor obstáculo es "externo" a los historiadores: la parálisis que atenaza al pensamiento crítico marxista desde 1989. Estamos convencidos de que la reacción no se hará esperar, porque sin la contribución del materialismo histórico es imposible saldar cuentas -no sólo historiográficamentecon el siglo XX y entrar en el siglo XXI, donde nos seguiremos encontraremos con realidades sociales que, en bastantes aspectos, son peores que las que dieron origen al marxismo en el siglo XIX, y contextualizaron las actuales ciencias sociales y humanas. Todo ello sin dejar de lado, claro está, los desmentidos dramáticos que el siglo XX está dando a las previsiones marxistas acerca de la inevitabilidad de la transición histórica del capitalismo al socialismo.

Así como los paradigmas generales, economicista y estructuralista, que han sobredeterminado el paradigma común de los historiadores del siglo $\mathrm{XX}$, matando el sujeto, han sido desechados en general por los historiadores, no ha ocurrido lo mismo con el paradigma neopositivista, de influencia más clandestina pero no menos eficaz. Romper con el positivismo "malo" (antiteórico y antihistoricista) sin abandonar el positivismo "bueno" (rigor crítico documental) es, en nuestra opinión, un paso obligado para entrar en el siglo XXI historiográfico, y poder así desarrollar -en otro contexto- aquellos elementos paradigmáticos de Annales y del materialismo histórico que, teniendo el consenso de la comunidad historiográfica, acabaron sepultados por el objetivismo cientifista de raíz positivista, economicista y estructuralista. Por todo ello, es recomendable remontarse a los orígenes de las dos grandes escuelas historiográficas del siglo XX, para ganar en perspectiva y poder así evaluar mejor lo que sirve y lo que no sirve, lo que hay que reflotar -y reformular- y lo que hay que desechar, con los ojos siempre puestos en el futuro.

Si decimos que no hay metas fatalmente pre-fijadas sino objetivos continuamente revisables, es que no podemos saber con certeza la configuración final del paradigma historiográfico en formación, ni el rol que en él jugarán las tradiciones del siglo XX, o las nuevas escuelas que puedan constituirse en los años próximos. Es la comunidad de historiadores quien decide, en última instancia, el camino a seguir, que nos puede llevar a un nuevo paradigma común con escuelas (como en la segunda mitad del siglo XX), a varios paradigmas contradictorios con escuelas (romanticismo versus positivismo en el siglo XIX), o a otra configuración específica del siglo XXI. Nuestra opción es clara: paradigma común con escuelas -posiblemente más numerosas y de menores dimensiones- que promuevan una ciencia histórica con sujeto: tolerante y con debate; innovadora y tradicional; empírica y teórica; unificada, interdisciplinar y global; beligerante contra el futuro inhumano que dicen que nos espera.

\section{6}

Los cambios socioculturales de los años 90 favorecen a la historia y a las ciencias del hombre.

Reinvidicamos un nuevo paradigma común que haga salir de las catacumbas a la historia y a las humanidades. La coyuntura mental de los años 90 es, en este sentido, más favorable que la coyuntura de los años 80, caracterizada por el "yupismo", la adoración del dinero y del poder, la ola conservadora de Thatcher y Reagan, que parecía culminar brillantemente, hacia 1989, devolviendo el Este a un capitalismo que de inmediato se manifestó especulativo, corrupto y mafioso. La reacción de los años 90 contra ese capitalismo salvaje e inhumano en el Este de Europa, y contra la corrupción política y financiera en el Sur de Europa, el movimiento politically correct en USA, las huelgas generales obreras y estudiantiles europeas contra el paro y los recortes sociales del Estado de bienestar, la revuelta de Chiapas, el auge de las Organizaciones No Gubernamentales y de la solidaridad con el Tercer Mundo, la búsqueda de un 
nuevo compromiso ético en las ciencias físicas, biológicas y de la salud, la contestación al posmodernismo -cuyas críticas es capital considerar- desde una nueva racionalidad, están creando un clima mental, intelectual y moral, muy diferente, menos individualista y más humanista, a medida que nos acercamos al año 2000. O la humanidad devuelve al hombre, y a su medio ambiente, al centro de interés de la activi-

\section{Bibliografía}

ANÓNIMO. "Histoire et sciences sociales: un tournant critique". Annales, $\mathrm{n}^{\circ}$ 6, 1989. p. 1317- 1323.

BARROS, Carlos. "Historia de las mentalidades, historia social". Historia Contemporánea, Bilbao, nº 9, 1993. p. 111-139.

"Historia de las mentalidades: posibilidades actuales". Problemas actuales de la Historia, Salamanca, 1993. p. 49-67.

. "La contribución de los terceros Annales y la historia de las mentalidades. 1969-1989". La otra historia sociedad, cultura y mentalidades, Bilbao, 1993. p. 87-118.

"La 'Nouvelle Histoire' y sus críticos". Revista d'Història Moderna. Manuscrits, Barcelona, $\mathrm{n}^{\circ}$ 9, 1991. p. 83-111.

"El 'tournant critique' de Annales". Revista de Història Medieval, Valencia, nº 2, 1991b. p. 193-197.

CHARTIER, Roger. "Converses, Història i antropologia". Manuscrits, $\mathrm{n}^{\circ} 11,1993$. p. 29-40.

FEBVRE, Lucien. Combates por la historia. Barcelona: Ariel, 1975. 246p. dad política y económica, o el descalabro final ecológico, demográfico, ético, social-, a manos de la tercera revolución tecnológica y de la prepotencia del Primer Mundo, está asegurado. La historia y las ciencias humanas tienen algo que decir, y van a decirlo, siempre y cuando el paradigma historiográfico culmine satisfactoriamente el cambio en curso, que no tiene meta pre-establecida: depende de nosotros.

KUHN, Thomas S. La estructura de las revoluciones científicas. México: FCE. 1975. 319p. Segundos pensamientos sobre paradigmas. Madrid, 1978. La función del dogma en la investigación científica. Valencia, 1979.

La tensión esencial. Estudios selectos sobre la tradición y el cambio en el ámbito de la ciencia. México: FCE, 1983. 380p.

LAKATOS, Imre. La metodología de los programas de investigación científica. Madrid: Alianza Editorial, 1983.

MINC, Alain. La nueva Edad Media. El gran vacío ideológico, Madrid, 1994

MORIN, Edgar. Introducción al pensamiento complejo, Barcelona: Gedisa, 1994. 167p.

SAMUEL, Raphael. Historia popular y teoría socialista. Barcelona: Crítica, 1984. 317p.

SNOW, C. P. Las dos culturas y un segundo enfoque, Madrid, 1977. 